\title{
A COMPREHENSIVE STUDY ON DIAGNOSTIC VALUE OF QUANTITATIVE C-REACTIVE PROTEIN MEASUREMENT IN ACUTE APPENDICITIS
}

\author{
M. Ramula ${ }^{1}$ Narayanaswamy Lakshmipathy², Karthik Arumugam ${ }^{3}$, Ashwini Krishnamurthy ${ }^{4}$ \\ ${ }^{1}$ Associate Professor, Department of General Surgery, Chengalpattu Medical College Hospital. \\ ${ }^{2}$ Assistant Professor, Department of General Surgery, Chengalpattu Medical College Hospital. \\ ${ }_{3}^{3}$ Assistant Professor, Department of General Surgery, Chengalpattu Medical College Hospital. \\ 4Junior Resident, Department of General Surgery, Chengalpattu Medical College Hospital.
}

\section{ABSTRACT}

\section{BACKGROUND}

Appendectomy is one of the commonest procedures in surgery. In spite of various investigations used to improve the accuracy of diagnosis, the rate of normal appendices removed is still about 15-30\%. Many studies have investigated the role of C-Reactive Protein (CRP) in acute appendicitis, but with conflicting results.

\section{METHODS}

In a prospective, double-blind study, blood for the measurement of serum C-reactive protein was collected preoperatively from patients before going to the operating theatre for appendectomy. The histopathology was grouped into positive (acute appendicitis) and negative (normal appendix) and this was correlated with CRP values.

\section{RESULTS}

CRP was normal in 14 out of 20 negative explorations (normal appendix on histopathology). The specificity and sensitivity of serum CRP was $58 \%$ and $91 \%$ respectively. The predictive value of a positive (raised CRP) and negative (normal CRP) test is $88 \%$ and $48 \%$ respectively.

\section{CONCLUSION}

We conclude that quantitative measurement of CRP value is helpful in the diagnosis of acute appendicitis. Routine CRP measurement helps surgeon to make the diagnosis of appendicitis.

\section{KEYWORDS}

Acute Appendicitis, C-Reactive Protein.

HOW TO CITE THIS ARTICLE: Ramula M, Lakshmipathy N, Arumugam K, et al. A comprehensive study on diagnostic value of quantitative C-reactive protein measurement in acute appendicitis. J. Evolution Med. Dent. Sci. 2016;5(69):4995-4998, DOI: $10.14260 /$ jemds/2016/1134

\section{INTRODUCTION}

Acute appendicitis is a clinical diagnosis and no laboratory or radiological tests are $100 \%$ accurate. ${ }^{1}$ Mild leucocytosis ranging from 10,000 to 18,000 is usually present in patients with acute, uncomplicated appendicitis, and is often accompanied by a moderate polymorphonuclear predominance.

Many studies have been published on quantitative analysis of C-reactive protein which is an acute phase reactant protein that is produced in the liver. Normal serum concentration is less than $10 \mathrm{mg} / 1$ mean is $6 \mathrm{mg} / \mathrm{L}$. 8-12 hours after infection or trauma, the increase of acute phase protein in liver, the CRP is more important in clinical practice. Production of CRP is controlled by Interleukin 6 and in few minutes increases from 10 to 1000 times. CRP is increased in infections, ${ }^{2}$ inflammatory arthritis, autoimmune disorders, neoplasia, pregnancy, and ageing. Immunoturbidimetric and immunonephelometric methods with high sensitivity are available. In older methods, qualitative and semi-quantitative measurement of CRP with agglutination are possible.

Financial or Other, Competing Interest: None.

Submission 22-07-2016, Peer Review 16-08-2016,

Acceptance 22-08-2016, Published 29-08-2016.

Corresponding Author:

Dr. M. Ramula

A-14, Old GST Road

Alagesan Nagar, Chengalpattu-603001.

E-mail: ramuladurai@gmail.com

DOI: $10.14260 /$ jemds/2016/1134

\begin{abstract}
AIM OF STUDY
Main stay of diagnosis of acute appendicitis is accurate history, clinical evaluation, and physical examination. It is further reinforced by laboratory investigation like raised leucocytes count. To avoid unnecessary removal of normal appendix more laboratory tests like C-Reactive Proteins (CRP) have been evolved.

Aim of the study is to find out the diagnostic value of quantitative CRP in suspected cases of acute appendicitis. Creactive protein is basically an acute phase reactant, which has been shown persistently elevated in cases of acute appendicitis. ${ }^{3}$ C-reactive protein had a sensitivity of $87 \%$ and specificity of $50 \%$ and is very helpful in the diagnosis of acute appendicitis with complications like perforation, but it does not replace the clinical skills of the surgeon. ${ }^{4}$ In this study, Creactive protein has been studied and correlated with clinical findings and confirmed by HPE.
\end{abstract}

\section{CLINICAL DIAGNOSIS}

The diagnosis of acute appendicitis made mainly based on clinical examination. ${ }^{5}$ Only laboratory investigations without any clinical grounds do not establish diagnosis. Moderate leucocytosis ranging from about 10,000-18,000 cells/cumm with neutrophilia is the common picture in acute appendicitis. With normal total and differential counts, the diagnosis of acute appendicitis is still a possibility. 


\section{C-Reactive Protein Levels}

C-reactive protein is basically an acute phase reactant, which has been to stay persistently elevated ${ }^{6}$ in cases of acute appendicitis unlike the total count, which progressively decreases with time and C-reactive protein had a sensitivity of $87 \%$ and specificity of $50 \%$. The diagnosis of appendicitis rests on a combination of clinical examination, leucocytosis, and elevated C-reactive protein.

C-reactive protein has been studied and correlated with clinical and HPE report postoperatively. The readings of CRP were ranging between 0 and $12.7 \mathrm{mg} / \mathrm{L}$ (mean $5.6 \mathrm{mg} / \mathrm{L}$ ) in patients with normal appendix and between $6-93.4 \mathrm{mg} / \mathrm{L}$ in patients with acute appendicitis.

CRP estimation required specialised laboratory equipment, which has now been resolved by using CRP kits.

\section{CONCLUSION}

CRP is elevated in any cause of acute inflammation. But, if clinical suspicion of appendicitis is not confirmed, CRP estimation provides the clue for acute appendicitis. Whereas leucocyte count was the investigation of choice in acute uncomplicated appendicitis. C-reactive protein correlated better with protracted inflammation and appendicular perforation.

\section{MATERIAL AND METHODS}

In this study, patients admitted in Chengalpattu Medical College during the period of 2014 and 2015 were included. This study was conducted in 100 patient admitted in surgical ward with diagnosis of acute appendicitis and this study was approved by Ethical Committee of our medical college and hospital. The patients were subjected to series of investigations including CRP, WBC count, and HPE postoperatively.

\section{Inclusion Criteria}

All patients with clinical signs and symptoms of acute appendicitis during the study period admitted to Department of General Surgery, Chengalpattu Medical College and Hospital. Patients diagnosed as appendicular mass or appendicular abscess and patients who were kept under observation were excluded.

\section{Mode of Selection of Study Subjects}

This is the prospective study done in Chengalpattu Medical College during the year 2014 and 2015 patient who were diagnosed clinically as acute appendicitis (physical examination and other investigations part deleted as suggested).

All patients were subjected to C-reactive protein estimation was done by sending blood sample of the patients to microbiology laboratory. Estimation done using serial dilution technique using C-reactive protein latex agglutination kits. Patients were considered as positive when CRP $>6 \mathrm{mg} / \mathrm{dL}$ and they were operated. Complete haemogram was done in all patients. WBC cutoff as $>10,000$ and neutrophil count as $>70 \%$ has been taken as selection of patients for surgery.

All patients who satisfy above criteria were subjected to emergency appendicectomy. The preoperative findings were noted with particular importance to features of inflammation of appendix. The final diagnosis of acute appendicitis was confirmed by HPE reported by Pathology Department of
Chengalpattu Medical College and Hospital. Postoperative CRP sample taken on the day of discharge.

\section{METHODS APPLIED FOR THE STUDY}

Following Statistical Methods were Employed in the Study

- Descriptive statistics.

- Chi-square test.

- Crosstabs analysis.

- Paired ' $t$ ' test.

- Sensitivity and specificity calculation.

$52 \%$ of the patients were between age group of $15-49 \mathrm{yrs}$. and $66 \%$ of the patient were under 30 yrs., $34 \%$ of patients were more than $30 \mathrm{yrs}$. This shows that appendicitis occurs at greater percentage in young patients than in the older age groups.

\begin{tabular}{|c|c|c|}
\hline CRP & Number & Percentage \\
\hline NEG & 0 & 0 \\
\hline$<6$ & 0 & 0 \\
\hline 6 to 12 & 34 & 34 \\
\hline 13 to 24 & 8 & 8 \\
\hline 25 to 48 & 22 & 22 \\
\hline 49 to 96 & 36 & 36 \\
\hline TOTAL & 100 & 100 \\
\hline \multicolumn{2}{|c|}{ Table 1: Preoperative CRP in Different Ranges } \\
\hline
\end{tabular}

This study shows $36 \%$ of the patients had CRP dilution of 49 to $96,34 \%$ of the patients has dilution between 6 to 12 and none of the patient had $<6$. Many studies have shown in negative appendectomies. The value of CRP usually less than $6 .^{7}$

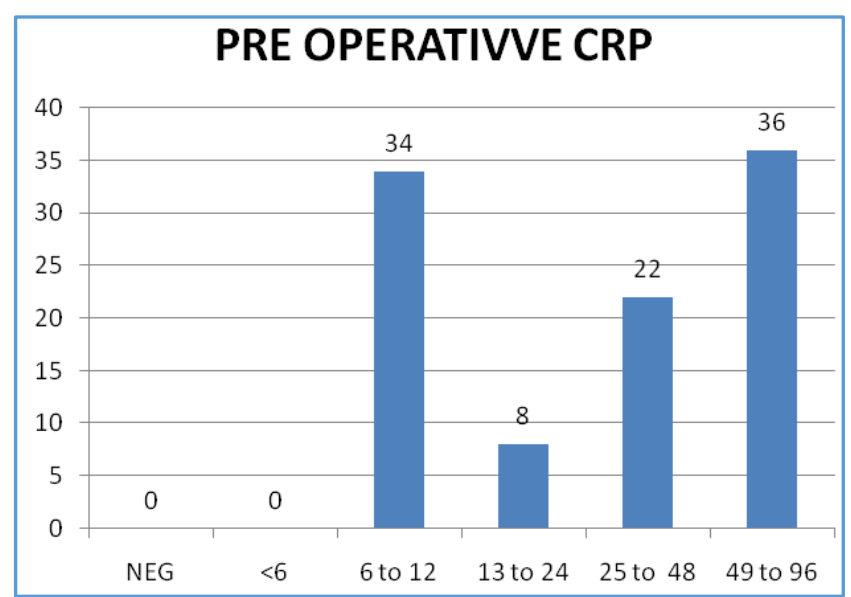

Graph 1: Preoperative CRP in Different Ranges

This study shows that in maximum 36 patients, the CRP value estimated was ranging from 49 to 96 ; in 34 patients, it was between 6 to 12 ; in 22 patients, the range was between 25 to 48 ; only 8 patients value ranging from 13 to 24 ; and in our selected group, none showed normal CRP of total 100 patients of this only 11 patients had normal appendix.

The value of $\mathrm{C}$-reactive protein as a guide for surgical intervention has been debated in many studies with varying results. In many studies, increase in CRP levels has been indicated in more advanced stage of appendicitis, since synthesis of CRP starts only after $4 \mathrm{hrs}$. of tissue injury and concluded that raised CRP is reliable indicator of acute appendicitis per operative value of CRP less than 6 rules out appendicitis. 


\begin{tabular}{|c|c|c|}
\hline CRP & Number & Percentage \\
\hline NEGATIVE & 44 & 44 \\
\hline$<6$ & 50 & 50 \\
\hline 6 to 12 & 6 & 6 \\
\hline 13 to 24 & 0 & 0 \\
\hline 25 to 48 & 0 & 0 \\
\hline 49 to 96 & 0 & 0 \\
\hline \multicolumn{2}{|c|}{ Table 2: Postoperative CRP in Different Ranges } \\
\hline
\end{tabular}

This study shows postoperative CRP level is reduced almost to negative in $94 \%$ of the patient in the $7^{\text {th }}$ day and only $6 \%$ of patient showing this mild elevation of CRP in the range of $6-12 \mathrm{mg} / \mathrm{dL}$ dilution.

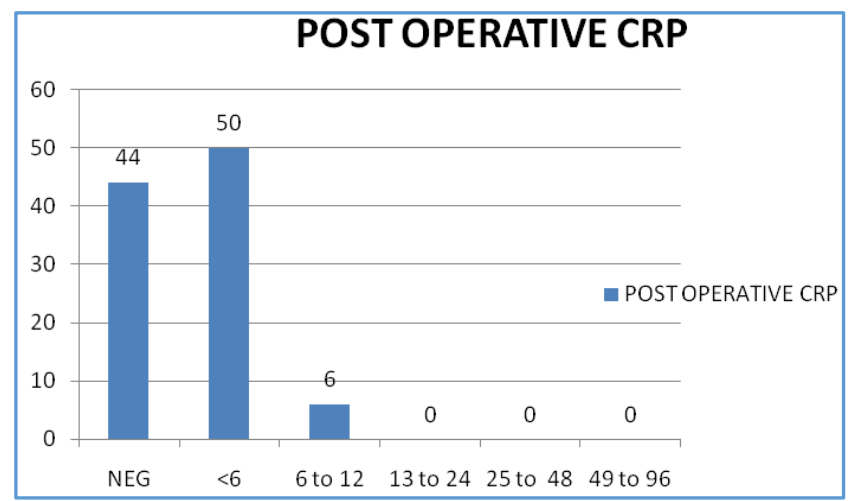

Graph 2: Postoperative CRP in Different Ranges

Postoperative graph showed negative CRP in 44 patients, $<6$ in 50 patients and only 6 patients showed value of 6 . The value of CRP acts as a guide for surgical intervention, $<6$ CRP value rules out appendicitis.

\begin{tabular}{|c|c|c|}
\hline CRP & Pre-OP CRP & Post-OP CRP \\
\hline$<6$ & 0 & 50 \\
\hline 13 to 24 & 8 & 0 \\
\hline 25 to 48 & 22 & 0 \\
\hline 49 to 96 & 36 & 0 \\
\hline 6 to 12 & 34 & 6 \\
\hline NEG & 0 & 44 \\
\hline TOTAL & $\mathbf{1 0 0}$ & $\mathbf{1 0 0}$ \\
\hline \multicolumn{2}{|c|}{ Table 3: Comparison of Preop and Postop CRP } \\
\hline
\end{tabular}

On comparing the preop and postop CRP levels, postoperative CRP are negative in almost $94 \%$ of patients.

The sensitivity of WBC count in diagnosing acute appendicitis is only $81.8 \%$.

While taking HPE as the gold standard test 10 , the specificity of the test is $83.3 \%$. The probability of having a patient suffering from acute appendicitis whose WBC count is $>10,000$ preop is $97 \%$ (PPV).

\begin{tabular}{|c|c|}
\hline Mean & 3.72 \\
\hline SD & 3.6 \\
\hline MEDIAN & 6 \\
\hline MODE & 6 \\
\hline N & 100 \\
\hline \multicolumn{2}{|c|}{ Data Analysis }
\end{tabular}

Postoperative "T" VALUE 5.06, " $\mathrm{t}$ ” table value at 99 1.671, $P$ value at 99 degrees of freedom is $<0.05$.

Since the calculated ' $t$ ' value is three times more than the table value, postoperative CRP is significantly reduced compared to mean preoperative CRP after the surgery on the $7^{\text {th }}$ day.

\begin{tabular}{|c|c|}
\hline Mean & 51.12 \\
\hline SD & 36.5114687 \\
\hline MEDIAN & 48 \\
\hline MODE & 96 \\
\hline $\mathrm{N}$ & 100 \\
\hline \multicolumn{2}{|c|}{ Hence it is Significant } \\
\hline
\end{tabular}

\section{DISCUSSION}

The value of CRP as a guide for surgical intervention has been debated in many studies with varying results. CRP level has been indicated in more advanced stage of appendicitis since synthesis of CRP starts only after 4 hrs., doubles up every $8 \mathrm{hrs}$. peaking in $24 \mathrm{hrs}$., and concluded that raised CRP is reliable indicator of acute appendicitis. ${ }^{8}$ Preoperative value of $<6$ rules out appendicitis. Studies with one random variable show that only raised CRP significantly vary between surgical treatment needed group and nonsurgical treatment group. ${ }^{9}$ In acute appendicitis, raised CRP acts like surgical indication marker, ${ }^{10}$ significantly raised level indicate later stage of appendicitis like perforation or gangrene.

In this study, $66 \%$ of patients were less than 30 yrs. of age showing acute appendicitis. Males (60\%) outnumbered females $(40 \%)$.

Preoperative CRP of all the study subjects were positive and hence they were taken as study subjects. All patients underwent emergency open appendicectomy and subjected to HPE evaluation.

Postoperatively, patients were treated with antibiotics. On the 7 th postoperative day, CRP samples were sent. Postoperative CRP values of these patients were 94\% were negative and $6 \%$ were CRP positive in the range of $6-12$ $\mathrm{mg} / \mathrm{dL}$.

About $88 \%$ of patients were positive as acute appendicitis in HPE and $12 \%$ of patients were negative in HPE.

The sensitivity of WBC count in diagnosing acute appendicitis is 6 only $81.8 \%$. While taking HPE as the gold standard test, the specificity of the test is $83.3 \%$.

The probability of having a patient suffering from acute appendicitis whose WBC count is $>10,000$, preop is $97 \%$ (PPV), so patients who had raised WBC counts only $40 \%$ maybe having acute appendicitis.

Since, positive predictive value of $\mathrm{WBC}$ count of $>10,000$ is $97 \%$. The combination of WBC count $>10,000$ can be taken as one of the reliable laboratory parameter of acute phase reactant. 11

CRP is positive in all the $100 \%$ of the study subjects and WBC $>10,000$ in $74 \%$ of the study subjects and neutrophil $>70 \%$ in eighty eight percentage of the study subjects, this clearly indicates that most of the patients had elevation of any one of the acute phase reactant.

There is significant reduction $94 \%$ in the CRP value on the 7 th postoperative period and HPE positive in $88 \%$ of the patients, so the diagnostic accuracy is $88 \%$.

Mean preoperative value is 51.12 and postoperative value is 3.72 and the standard deviation of pre and postoperative is 36.5 and 3.6, respectively.

" $\mathrm{t}$ " table value at 99 is 1.671 and the P VALUE AT 99 degree of freedom is $\mathrm{p}<0.05$.

Since the calculated ' $\mathrm{t}$ ' value is three times more than the table value. Postoperative CRP is significantly reduced compared to mean preoperative CRP after the surgery on the $7^{\text {th }}$ day. 


\section{Hence it is Significant}

Many inflammatory markers are being used now in the diagnosis of suspected appendicitis, but CRP levels reinforces the diagnosis and consistent with severity of appendicitis. This study clearly shows the raised CRP predicts the severity of appendicitis.

\section{CONCLUSION}

1. CRP can be taken as an important laboratory parameter for diagnosing acute appendicitis because in our study all the $100 \%$ had an elevated CRP.

2. HPE is the gold standard in confirming the diagnosing acute appendicitis, elevated CRP will be helpful in pickup patients with acute appendicitis. Since CRP elevated in $100 \%$ of the study subject and $88 \%$ of the patients who had HPE also positive, so the diagnostic accuracy of the test is $88 \%$. CRP is an important acute phase reactant in diagnosing acute appendicitis.

3. Raised CRP value is directly related to severity of inflammation $(\mathrm{p}<0.05)$. CRP monitoring enhance the diagnostic accuracy of acute appendicitis to $88 \%$, thus unnecessary removal of the normal appendix can be reduced and raised CRP to be considered as surgical indication marker for acute appendicitis.

\section{REFERENCES}

1. Albu E, Miller BM, Choi Y, et al. Diagnostic value of creactive protein in acute appendicitis. Diseases of Colon and Rectum 1994;37(1):49-51.

2. Gronroos JM, Gronroos P. Leucocyte count and C-reactive protein in the diagnosis of acute appendicitis. BJS 1999; 86(4):501-4.

2. Petroianu A. Diagnosis of acute appendicitis. International Journal of Surgery 2012;10(3):115-9.
3. Kyriakidis AV, Alexandris I, Papoulia P, et al. C-reactive protein aids in right lower quadrant pain. Annals of Gastroenterology 2010;23(4):307-10.

4. Hoffmann J, Rasmussen 00. Aids in the diagnosis of acute appendicitis. Br J Surgery 1989;76(8):774-9.

5. Gurleyik E, Gurleyik G, Unalmiser S. Accuracy of serum Creactive protein measurements in diagnosis of acute appendicitis compared with surgeon's clinical impression. Dis Colon Rectum 1995;38(12):1270-4.

6. Thompson MM, Underwood MJ, Dookeron KA, et al. Role of sequential leucocyte counts and C-reactive protein measurements in acute appendicitis. $\mathrm{Br} \mathrm{J}$ Surgery 1992;79(8):822-4.

7. Zarandi NP, Parsijani PV, Bolandparvaz S, et al. Accuracy of surgeon's intraoperation diagnosis of acute appendicitis compared with the histopathology results. Bull Emerg Trauma 2014;2(1):15-21.

8. Cardall T, Glasser J, Guss DA. Clinical value of total white blood count and temperature in the evaluation of patients with suspected appendicitis. Acad Emerg Med 2004;11(10):1021-7.

9. Andersson RE, Hugander AP, Ghazi SH, et al. Diagnostic value of disease history, clinical presentation, and inflammatory parameters of appendicitis. World J Sur 1999;23(2):133-140.

10. Al-Saigh AH. C-reactive protein in the differential diagnosis of acute abdomen especially appendicitis. J R Coll Sur Edinb 1992;37(4):238-40.

11. Yokoyama S, Takifuj K, Hotta T, et al. C-reactive protein is an independent surgical indication marker for appendicitis: a retrospective study. World Journal of Emergency Surgery 2009;4:36. 